\title{
CHALLENGING EVOLUTIONARY PSYCHOLOGY WITH THE ETERNALIST VIEW OF THE WORLD
}

\section{César Fernando Meurer}

Doutor em Filosofia. Pós-doutorando (PNPD/Capes) junto ao Programa de Pós-Graduação em Filosofia da Universidade Federal de Uberlândia cfmeurer@yahoo.com.br

\begin{abstract}
Evolutionary psychology conceives the human mind as massively modularly organized. I propose here that the eternalist view of time, on which the world is a four-dimensional block comprised of an innumerable amount of time-slices, poses a challenge to this view. After presenting these two positions - along which it becomes clear that the question 'How does a massively modular mind handle such a world?' should not be dismissed as trivial -, I explore one possible answer: that our mind counts on a module for processing temporal parts of events. A computational explanation of this mechanism is outlined. In short, it performs three sequential steps: it tracks the present, it links temporal parts that were already present and, based just on the pattern of motion that grouping manifests, it predicts forthcoming temporal parts of the target event (i.e., temporal parts that may be present shortly). Drawing on empirical studies, I suggest that such a module could be seen as maximizing fitness by (i) assigning intentionality to events that present motion with biological timing, and (ii) processing events from the framework of a third person.
\end{abstract}

Keywords: Modularity of mind. Four-dimensionalism. Motion. Temporal parts.

\section{DESAFIANDO A PSICOLOGIA EVOLUCIONÁRIA COM A VISÃO ETERNALISTA DO MUNDO}

Resumo: A psicologia evolucionária considera que a mente humana é massivamente modular. Proponho aqui que a visão eternalista do tempo, segundo a qual o mundo é um bloco de quatro dimensões composto por incontáveis partes temporais, apresenta um desafio para a psicologia evolucionária. Depois de apresentar essas duas posições - o que deixa claro que a pergunta 'Como uma mente massivamente modular lida com tal mundo?' não deve ser descartada como trivial -, exploro uma possível resposta: que a mente humana conta com um módulo para processar partes temporais de eventos. Uma explanação computacional desse mecanismo é esboçada. Em síntese, ele executa três ações: rastreia a presente parte temporal do evento, vincula partes temporais que já estiveram presentes e, com base apenas no padrão de movimento que esse agrupamento manifesta, prediz partes temporais vindouras do evento em questão. Amparado em estudos empíricos, sugiro que esse módulo maximiza o fitness mediante (i) atribuição de intencionalidade a eventos que apresentam movimento biológico, e (ii) processamento de eventos a partir do quadro de referência de outra pessoa.

Palavras-chave: Modularidade da mente. Quadridimensionalismo. Movimento. Partes temporais. 


\section{Introduction}

Tooby (1985) envisions the human mind "as an integrated architecture of different special-purpose mechanisms, 'designed' to solve various adaptive problems". This architecture, he elaborates, "has been shaped by natural selection to structure interactions among different mechanisms so that they function particularly harmoniously when confronting commonly recurring (across generations) adaptive situations" (Tooby, 1985, pp. 70-71). In the following years, this idea would become the hard core of a research program called Evolutionary psychology. The protective belt of this program has been developed since then. In section 2, below, I use Lakatos' framework (Lakatos, 1970a; 1970b) to describe this tradition.

Evolutionary psychology can be thought of as an architectonic claim: the architecture of human mind is massively modular. This position can be challenged with another architectonic claim: the world is a four-dimensional manifold entirely given. Widely known as Eternalism, this view can be traced back to 1908, when the German mathematician Hermann Minkowski (1923), under the influence of Einstein's theory of special relativity, proposed a kind of union of space and time that transforms the objective world into a four-dimensional block that "simply is, it does not happen" (Weyl, 1949, p. 116). I shall dedicate section 3 to the presentation of eternalism.

How should evolutionary psychologists think about eternalism? That is, how does a mind comprised of evolved information processing mechanisms handle the four-dimensional block? In section 4, I explore one possible answer: that human mind counts on a module for processing temporal parts of events. ${ }^{1}$ To address this in a constructive way, I will sketch a computational explanation - an account of what this hypothetical mechanism does and why (Marr, 1982). In short, the module performs three sequential steps: it tracks the present temporal part of a target event; it links temporal parts that were already present and, based on the pattern of motion that grouping manifests, it predicts forthcoming temporal parts of that event (i.e., temporal parts that are likely to be present soon). Drawing on empirical studies, I suggest that such a module maximizes fitness by (i) assigning intentionality to events whose grouping of temporal parts shows motion with biological timing, and (ii) processing events from the framework of a third person.

\section{Evolutionary psychology: a progressive research program}

The scientific status of evolutionary psychology is best appreciated in the light of Lakatos' philosophy of science (1970a; 1970b), on which research programs have a hard core - the leading and irrefutable idea -, and are developed through a negative and a positive heuristic. The negative heuristic signals the commitment to retain the hard core, while the positive heuristic labels the permanent task of adjusting and re-adjusting refutable hypothesis within the protective belt (Lakatos, $1970 a$, p. 135). For Lakatos, a research program is progressive "as long as its

\footnotetext{
1 I use 'event' and 'object' interchangeably, since "physical objects, conceived four-dimensionally in spacetime, are not to be distinguished from events" (Quine, 1960, §36, p. 170).
} 
theoretical growth anticipates its empirical growth, that is, as long as it keeps predicting novel facts with some success" (Lakatos, 1970b, p. 100). In contrast, programs whose theoretical growth occurs only by means of post-hoc explanations are regarded by Lakatos as stagnating.

How should we understand the hard core of evolutionary psychology? Pinker (1997) rightly notes that this tradition brings together two scientific revolutions of the second half of the 20th century: the cognitive revolution, "which explains the mechanisms of thought and emotion in terms of information and computation", and the revolution in evolutionary biology, "which explains the complex adaptive design of living things in terms of selection among replicators" (Pinker, 1997, p. 23). Indeed, in the early $90 \mathrm{~s}$ it was already clear that "the additional knowledge that evolutionary biology has to offer" to psychology may further not only the "understanding of the process that designed the human mind", but also "the discovery of its architecture". Consequently, a primary focus of evolutionary psychology is "the evolved information-processing mechanisms that comprise the human mind" (Cosmides, Tooby and Barkow, 1992, p. 03).

Cosmides and Tooby (1994) argue that evolution tends to favor specialized domain-specific modules rather than domain-general systems because [i] in terms of reliability, speed, and efficiency, domain-specific modules are a superior engineering solution; [ii] modules were able to accumulate, throughout evolutionary time, domainspecific criteria of success and failure; [iii] since modules are equipped with domainspecific information compiled over many generations, they are able to keep on functioning when environmental stimuli are insufficient or diffuse; and [iv] a massively modular architecture can handle complex data situations, in which alternatives increase exponentially.

More recently, Carruthers (2006) has put forward a different set of arguments for the massive modularity. On the first, called the 'argument from design', biological systems evolved in such a way that they have massively modular organization when complex. Since the human mind is a complex biological system, it follows that it must be massively modularly organized (Carruthers, 2006, pp. 12-28). The second, the 'argument from animals', starts with an inference to the best explanation: minds of non-human animals that possess a central nervous system are massively modular in their organization. Given that biological structures are in general preserved in evolutionary transitions from one to another species, it follows that human mind will also be highly modular (Carruthers, 2006, pp. 29-35 and pp. 65-149). Carruthers' third argument deals with computational tractability. It has two premises. First, the mind is realized in computational processes, and second, the computations must be carried out in a finite time. Given that only processes that are modular to a certain degree are suitably tractable, our mind must be made up by modules (Carruthers, 2006, pp. 44-61).

Instead of discussing these two sets of arguments, I just want to say that they converge on the hard core of the program: the human mind contains a great many modules, and these can be understood as "specialized systems that can be described in computational terms and that have been shaped by natural selection to perform specific functions" (Eraña, 2012, p. 857).

For any research program, it is essential to link the hard core to empirical data. As noted above, if a theory manages to anticipate new facts then the program gains a 'progressive' status. As for evolutionary psychology, much of its growth occurs in 
the following way: a domain specific module is proposed (theoretical growth), which encourages predictions. Eventually, some of these predictions find empirical corroboration (empirical growth). Here is a sample of recent cases in which the theoretical growth has preceded empirical growth: a module for detecting cheating (Cosmides and Tooby, 1992); for sexual preference (Buss, 1992; 2008; 2016); for sexual disgust (Fessler and Navarrete, 2003; Tybur, Lieberman and Griskevicius, 2009); for ostracism prevention (Kurzban and Leary, 2001; Chester and De Wall, 2017), for kinship detection (Lieberman, Tooby and Cosmides, 2007; Park, Schaller and Van Vugt, 2008), for assessing others' ability to fight (Sell et al., 2009; Sell et al., 2010; Little et al., 2015).

Given these successes, it is clear that evolutionary psychology is today a rapidly growing research program, and meets the requirements that Lakatos set for progressive programs. Arguably, this is the best we can achieve in scientific research: move on with empirical corroboration. However, evolutionary psychology's relation to eternalism has not yet been discussed.

\section{Eternalism: the world as a four-dimensional manifold}

What is the fundamental nature of temporal reality? Philosophers and physicists have long been interested in the nature of time. A popular view is Eternalism, the idea that the world is a four-dimensional manifold. In this section, I present this view in a way that highlights the challenge it poses for evolutionary psychology. In a nutshell: rooted in a realistic interpretation of Einstein's theory of Special Relativity (Einstein, 1989), it understands physical objects as spread out across time without any dynamic motion.

The realist view of Special Relativity conceives space-time as ontologically given, not as a mere representation of the world, but how the world actually is. ${ }^{2}$ Minkowski (1923, p. 76) set the stage for this interpretation: "space, by itself, and time by itself", he said at the beginning of that now famous conference given in 1908, "are doomed to fade away into mere shadows, and only a kind of union of the two will preserve an independent reality". Time, he claims, is necessary since anything in the world "invariably includes places and times in combination". He uses $x, y, z$ as coordinates for space and $t$ for time in his most important metaphysical statement: "A point of space at a point of time, that is, a system of values $x, y, z, t, I$ will call a world-point. The multiplicity of all thinkable $x, y, z, t$ systems of values we will christen the world" (Minkowski, 1923, p. 76).

One conceivable world-point coincides with the occurrence of my birth. Another coincides with my typing of this sentence, and another coincides with the occasion on which you are reading it. What is at stake here? In short, if the world is the sum of all thinkable systems of values, as Minkowski put it, then it is bigger than the present world. The present (the 'now', if you wish) turns out to be nothing but one

\footnotetext{
${ }^{2}$ Craig (2008) points out that there are at least three interpretations of Special Relativity in the literature. Besides the view I'm following in this paper, there is an instrumentalist view, which takes space-time only as a theoretical construct, "a geometrical representation of a theory which is really about physical objects enduring through time" (p. 12), and a Lorentzian view, which preserves "the classical notions of space and time on metaphysically intuitive grounds" (p. 14). Craig also notes that Einstein himself had initially an instrumentalist view, but ended up committed to the realist approach. Not surprisingly, the realist view "has come to be the dominant mode of presentation and discussion of relativity" (p. 13).
} 
among many slices for time. The totality of these temporal slices can be thought of as a four-dimensional manifold.

Why exactly does the Special Theory of Relativity, when interpreted realistically, imply the eternalist view of the world? In a text accessible to a wider audience, Einstein (1997) offers a well-articulated presentation of the relativity of simultaneity. He invites the reader to suppose a long train travelling with a constant velocity. People inside that train may easily take the train itself as reference. It turns out that two occurrences (in Einstein's example, two strokes of lightening A and B) that are simultaneous with reference to the railway embankment are not simultaneous relatively to the train. In other words, when the train is the referencebody, lightening flash B takes place earlier than A (Einstein, 1997, pp. 274-276). Had we a second train, similar to the first one, travelling in parallel but in the opposite direction, then we would have a case in which $A$ is earlier than $B$. For some, this may be puzzling: from the embankment, $A$ and $B$ are simultaneous; from the first train, $B$ is earlier than $A$; from the second train, $A$ is earlier than $B$.

There is no puzzle for those who accept Minkowski's realist interpretation: all world-points are real, no matter how close or far they are, spatially and temporally, from a certain reference (e.g. your current position). All time-slices, and not only what is present in your 'now', are real. Each of the three reference-bodies (the embankment, the first and the second train) gives you a "different three-dimensional cross-section of the four-dimensional world" (Petkov, 2006, p. 214). Echoing Einstein: choose the reference-body you prefer, but know that each one has its own time. The set of things that are simultaneous in one frame may not be simultaneous when you take a different reference. Each 'now' encompasses different things. The idea of an absolute simultaneity - a universal 'now', spread as a worldwide instant - has been ruled out. Along these lines, we have strong reasons to think that temporally distant objects are as real as spatially distant objects. As Sider (2008, p. 243) puts it "I think temporally distant objects, such as dinosaurs, are just as real as objects we experience now. The fact that a dinosaur is far away in time doesn't make it any less real $[\ldots] "$.

If we accept this account, physical objects are spread out across time, that is, they have temporal parts (Effingham, 2012). Of course any spatially extended object also has spatial parts. "Such as spatial parts are smaller than the whole object in spatial dimensions, temporal parts are smaller than the whole object in the temporal dimension" (Sider, 2008, p. 242). The very first temporal part of my teacup coincides with the instant in which it came to existence, so to say. There are countless temporal parts between the teacup there-earlier (in the factory where it was manufactured) and the teacup here-now (on my desk). Also, there are countless forthcoming temporal parts, each one slightly different from the previous one.

Understood as a spacetime worm comprised by numerous temporal parts (that is, an event) my teacup never moves. This applies to everything, living beings included. It is true that each temporal part is in a different position $x, y, z, t$. This, however, does not imply dynamic motion. Indeed, since eternalism conceives the world as entirely given, there is no room for dynamic motion. 
What about the present (the 'now')? Isn't it somehow distinct or special? Most eternalists take 'present' as an indexical. ${ }^{3}$ This account, which is also known as token-reflexive, has been formulated several times over the last decades. In Williams' words: "The term 'the present' is the conventional way of designating the crosssection of events which are simultaneous with the uttering of the phrase" (Williams, 1951, p. 463; See also Smart, 1968, p. 255; Bourne, 2002, p. 359; Arthur, 2006, p. 131). According to this conception, there is nothing metaphysically special about the present moment. It is just the case that your current temporal part is confined in the time-slice you label 'now', and coexists with a set of objects that have temporal parts in the same time-slice as well.

Einstein taught that any and every meaningful statement of time is related to a reference. So, those who hold an indexical account need to relativize the present to a frame of reference. Options are plentiful and include, for example, the instant I pronounce 'now', the moment someone knocks the door, the occasion that traffic light turns green... I submit that in many cases the subject herself - a notion of "Ihere-now", in an ecological sense (Neisser, 1988, p. 36), or "my current temporal part" (Sider, 2001, p. 56), or "subject at Degree 1" (Peacocke, 2014, pp. 35-36) - is discreetly called to serve as parameter of simultaneity (reference-body).

To sum up: on eternalist accounts, the world is a four-dimensional manifold and one time-slice is currently present. Previous and subsequent time-slices are as real as the current one. The same, at the level of objects: any physical object in the world is a space-time worm comprised by numerous temporal parts. A multitude of objects have temporal parts in the present time-slice. How does a massively modular mind handle such a world? More specifically: how does a massively modular mind process objects that have temporal parts in the present time-slice? Without dismissing the question as trivial, ${ }^{4}$ what could and evolutionary psychologist reply? Throughout the next section, I explore one possible answer.

\section{A module for event processing}

Evolutionary psychology claims that the architecture of human mind is massively modular. Eternalism states that the world is a four-dimensional block comprised of time-slices, one of them present now. Speculating how the mind handles such a world, an evolutionary psychologist may hypothesize that it relies on a module for processing temporal parts of events. Considering that Lakatos' positive heuristic instructs the production and evaluation of falsifiable hypothesis in the protective belt, this seems the right way to go. Throughout this section, I attempt to develop this idea - a mechanism for event processing - in a positive way. I'm going

\footnotetext{
${ }^{3}$ Some eternalists want 'present' to be a referential term. Moving Spotlight Theorists, for instance, claim that the present is distinct due to a temporary A-property: presentness. This property is mindindependent, and it is objectively moving like a spotlight from one time-slice to the next. In other words: time-slices, all equally real, instantiate one after another this A-temporary determination. For a detailed discussion of Moving Spotlight Theory, see Skow (2015, pp. 44-69). The debate between different accounts of the present within eternalism is not settled and, for the purposes of this paper, we need not to choose or exclude any position.
}

${ }^{4}$ Those who don't recognize the challenge will be led to admit systematic illusions. Doing so, one loses the criterion by which true experiences can be distinguished from illusory experiences. In short, one loses the world. 
to sketch a computational explanation of this hypothetical module, which I call Event Processor.

According to Marr (1982, p. 22), a computational explanation describes "what the device does and why". The following guidelines, proposed by Anderson (1990, p. 29 ), allow us to construct such an account: 1) Precisely specify what the goals of the cognitive system are; 2) Develop model of the environment to which the system must adapt; 3) Make the minimal assumptions about computational limitations; 4) Derive the optimal behavioral function, given items 1 through 3; 5) Examine the empirical literature to see if the predictions of the behavioral function are confirmed; 6 ) If the predictions are incorrect, iterate. For Anderson (1990, p. 28), these guidelines are governed by a general principle, namely, that any cognitive system operates "to optimize adaptation of the behavior of the organism".

\subsection{The goals}

The Event Processor seeks [i] to track the present temporal part of a target event; [ii] to link temporal parts that were already present and, based on the pattern of motion this grouping manifests, [iii] to predict forthcoming temporal parts of that event (i.e., temporal parts that may soon be present).

How the module functions can be seen by considering the following three examples. First, a case of rigid body dynamics: consider a person observing a ball rolling along a flat surface. The ball has temporal parts spread out over instants of time $(t 1, t 2, t 3$ etc.), each of which is present once. The event unfolds in such a way that the observer could truly say: now $\mathrm{t} 1$ is present, now $\mathrm{t} 2$... now $\mathrm{t} 3$... After a few moments, she is able to predict forthcoming temporal parts of that ball. Second, a case of biological motion: observer is watching her baby crawling in the living room. The same as with the previous case: this event - the baby - has temporal parts, one after another present, and soon the observer is able to predict forthcoming temporal parts of the event. Third, a case with a stationary object: a cup of tea on a table. This object also has temporal parts, each of them in a different time-slice and describable by means of a different system of values $x, y, z, t$. Here, Event Processor does its job in exactly the same way as in the previous cases: based on the pattern of motion extracted from some temporal parts linked together, the mechanism predicts upcoming temporal parts.

The first goal (to track the present) requires a parameter of simultaneity (a reference). Arguably, our most basic parameter is a sense of I-here-now, and it becomes very difficult to track the present when this sense is somehow compromised. Consider schizophrenia: on the one hand, fMRI studies show that "the general neuropathology in schizophrenia alters the neural system configurations associated with self-representation" (Liu, Corbera and Wexler, 2014, p. 169). On the other hand, this condition brings about a kind of suspension of temporal flow (Fouks, Guilbert and Montot, 1989; Urfer, 2001). Silvano Arieti (1966), renowned Italian psychiatrist, reported that people with schizophrenia perceive the environment in fragments without continuity in space-time. Nowadays, it is well known that schizophrenic persons "describe their sense of temporal reality as 'things to a standstill', 'immobility, but not calm', 'time going back to the same moment over and over', 'people like statues', 'frozen moment', 'out of time', 'marmoreal', 'unreal stillness"' (Stanghellini and Rosfort, 2013, p. 240). The point is: if we accept that schizophrenia is a case in which the sense of I-here-now no longer functions as a 
parameter of simultaneity, then the suspension of temporal flow and all other reported difficulties related to time and motion become understandable.

The grouping of temporal parts that were already present is a matter for future research. It shall be explained without resorting to the doctrine of the specious present, which is indeed empirically problematic (Di Lollo, 1980; Di Lollo and Wilson, 1978). Arstila's account for temporal phenomenology within a framework where contents are confined to snapshots (Arstila, 2018) seems empirically adequate and also compatible with the major theories of consciousness (e.g. the dissociative theory, the global workspace theory and the higher-order theories). The key-point of grouping temporal parts is the extraction, so to say, of a pattern of motion. This is all the module considers to predict coming temporal parts of an object.

\subsection{A model of the environment}

Eternalism provides a detailed understanding of the architecture of the world, one that is in harmony with contemporary physics.

\subsection{Computational limitations}

Although computational limitations are not a concern at the most abstract level of explanation (Maar, 1982; Anderson, 1990), they are still controversial within computationalist philosophy of mind. Both Fodor and his followers, and evolutionary psychologists agree on one fundamental point - that a non-modular cognitive system is computationally infeasible -, but each group presents a different solution. By endorsing a strict notion of module (modules are informationally encapsulated), Fodor $(1983 ; 2000)$ rejects computationalism and instead puts his trust in the existence of central systems. Evolutionary psychologists, on the other hand, endorse a less strict notion of module (modules can receive inputs from each other), which leads to the inverse result: rejection of the idea of central systems and confidence in computationalism.

Fodorians hold that "the key to modularity is informational encapsulation" (Fodor, 1983, p. 98 and 2000, p. 56). Evolutionary psychologists agree that some modules may be encapsulated this way, but others are likely to receive information. Carruthers (2006) makes the point by distinguishing between narrow and wide-scope encapsulation. "In its narrow-scope form", he explains, "an encapsulated system would be this: concerning most of the information held in the mind, the system in question can't be affected by that information in the course of its processing". A widescope encapsulated system, on the other hand, "is such that it can't be affected by most of the information held in the mind in the course of its processing" (Carruthers, 2006, p. 58). In a later publication he emphasizes the importance of redefining the notion of encapsulation:

The challenge to anyone wishing to defend a thesis of massive mental modularity is then to answer the Fodorian arguments against centralsystems modularity while weakening the Fodorian notion of 'module' as little as possible (and in particular, while retaining the core idea that modules are encapsulated processing systems) (Carruthers, 2008, p. 293). 
That a certain module receives inputs from other modules does not imply that the computation this mechanism performs is accessible to those other modules. According to Carruthers (2006), a module is frugal in terms of information and consumption of cognitive resources, and keeps its internal operations inaccessible to other modules. "The thesis of massive mental modularity is then the claim that the mind is composed of many functionally isolable processing systems which possess such properties, and which have multiple input and output connections with others" (Carruthers, 2006, p. xii).

\subsection{Optimal behavioral functions}

An optimal behavioral function is a prompt response under certain conditions. It reveals bits of the specific knowledge the mechanism has accumulated over many generations. It is a function in the sense of a strategy, a policy, a rule. And it is optimal in the sense of fitness maximization (Birch, 2016; Davies, Krebs and West, 2012).

Event Processor, the module l'm describing here, maximizes fitness by (a) assigning intentionality to events that present motion with biological timing, and (b) processing events from the frame of a third person.

\subsection{Support from the empirical literature}

According to Anderson's fifth guideline we should expect predictions about behavioral functions to be corroborated by empirical evidence.

\section{a) Motion with biological timing and intentionality}

Some of the objects that surround us manifest a pattern of motion that gets classified as 'biological'. Empirical studies with point-light stimuli in newborns provide support for the idea that humans are able to detect this pattern from birth (Bided-Ildei et al., 2014). Similarly, adults not only detect this pattern quickly and almost without effort, but also associate it with intentions (Barrett et al., 2005; Troje and Westhoff, 2006).

According to Pyles et al. (2007, p. 2788) "kinematics alone (without any explicit shape or social interaction) is sufficient to generate a percept of animacy". They came to this conclusion through an empirical study with point-light animations whose body structure resembles no living being. Empirical findings like this one support the idea that our mind distinguishes biological motion solely on the basis of differences over a series of temporal parts linked together. Along the same lines, Troje (2008) argues that biological motion is processed in four sequential stages (/levels): (1) Detection of animate motion: this stage is automatic, fast, and independent of the shape of the creature; (2) Basic level agent recognition: "Once a living creature is detected, its movements can be used to perceptually organize it into a coherent, articulated body structure, resulting in a basic level agent recognition" ( $p$. 311). (3) Detection of the action: "On this level, structural and kinematic information is integrated into a system that classifies and categorizes actions and events" (p. 311);

(4) Style recognition: at this stage, the perceiver is "able to use motion as a source of 
information about individual identity, gender, age, emotional state, and personality traits, and as a complex means for signaling and communications" (p. 312).

Supported by a consistent and extensive meta-analysis of evolutionary literature, Barrett et al. (2005) singled out six basic categories of biological motion: chasing, fighting, courting, following, guarding, playing. These categories, they stress, "account for a great deal of natural animate motion, especially motion with significant adaptive costs, benefits, and risks" (p. 317). They found that adults and children are able to distinguish, on the basis of motion cues alone, between the above-mentioned categories. Based on results of a series of experiments conducted both with adults and children from Berlin (Germany) and with adults and children from the Shuar tribe (a tribe of hunter-horticulturalists in the Amazonian Rainforest, in southeastern Ecuador), Barrett and colleagues infer: "motion schemas for chasing, fighting, following, and playing are not culturally contingent but may develop reliably as evolved adaptations for inferring intentions from physical motion trajectories" (Barrett et al., 2005, p. 327).

Considering this picture, one may wonder: on what basis does the mind assign intentionality to certain trajectories? I suggest that this is accomplished exclusively through motion cues. A cognitive mechanism (Event Processor) may have evolved this behavioral function. Indeed, attribution of intentionality is consistently advantageous when it comes to predictions about a living being (Pavlova, 2012) and so can be seen as an optimal behavioral function.

\section{b) Processing events from a different framework}

The second behavioral function asserts that the Event Processor maximizes fitness by processing events from the frame of another subject. Here is the idea by means of an example: consider a scenario with two human beings ( $A$ and $B$ ) attend to a certain event. Obviously, the subjects are at different world-points (Minkowski: a world-point is a system of values $x, y, z$, and $t$ ). Let's also say they are not tracking the present throughout exactly the same series of time-slices (Several possible reasons: One of them may have arrived later or left earlier; One may have a better spot; One may have missed some intermediate temporal parts of the target event etc.). Assuming that the mind of both, $\mathrm{A}$ and $\mathrm{B}$, counts on a module Event Processor, we expect that both mechanisms will deliver predictions of forthcoming temporal parts of that event. Given all the circumstantial differences, the predictions may diverge.

The key idea here is: A's module is able to do its job (track, link, predict) from B's perspective and vice-versa. Kovács, Téglás and Endress (2010) produced empirical data supporting the hypothesis that in a shared scenario humans automatically compute and store beliefs of other agents. The module l'm describing can account for this computation quite parsimoniously. All we need is the ability to compute in the first and third person. When I say 'computing in first person', I mean Event Processor doing its job from its own world-point (I-here-now as parameter). Computing in third person means the module doing its job from the world-point of another agent (She-there-now as parameter).

Kovács, Téglás and Endress (henceforth KTE) conducted a visual detection task in which 24 adults watched 40 short animated movies (18.4s each) involving an agent (a character that appears in the animation), a ball (size of a tennis ball), and an 
occluder (size of a shoebox lid) placed on a table. Each movie begins with the same back plot: (1) the agent enters the scene from the left and places the ball on the table, in front of the occluder; (2) the ball rolls behind the occluder. After this, the movies continued in four different ways (/belief conditions). For each belief condition, I present an account with Event Processor.

First belief condition: (3) the agent leaves the scene for a while; (4) the agent returns; (5) the occluder is lowered and the ball is there. KTE labeled this condition $\mathrm{P}+\mathrm{A}+$, meaning the Participant (the human watching the movie) believed the ball was indeed behind the occluder and, additionally, may have had a second order belief: the Agent (the character in the animation) also "believes" the ball is behind the occluder. Now, the account with the Event Processor: the Participant is processing the event 'ball' both in first person (I-here-now as reference) and in third person (Agent-there-now as reference), and the predictions match (both computations predicted forthcoming temporal parts of the ball behind the occluder). Notice that the Agent left the scene for a few moments (3). This means that computations in third person grouped fewer temporal parts than computations in first person.

Second belief condition: (3) the ball continues to roll until it leaves the scene on the right; (4) the Agent leaves the scene; (4) the Agent returns; (5) the occluder is lowered and the ball is there. KTE labeled this condition P-A-, meaning the Participant believed the ball was not behind the occluder and, additionally, had a second order belief: the Agent also "believes" the ball is not behind the occluder. The account with the Event Processor is similar to that of the first condition: running both in first and in third person, the mechanism predicted the ball would not be behind the occluder.

Third belief condition: (3) the Agent leaves the scene; (4) the ball rolls out of the scene on the right; (5) the Agent returns; (6) the occluder is lowered and the ball is there. This condition is labeled P-A+ (Participant believed the ball was not behind the occluder and, additionally, had the belief that the Agent beliefs the ball is behind the occluder). Computing in first person, Event Processor performed its job and predicted forthcoming temporal parts of the ball wouldn't be behind the occluder. Computing in third person, and therefore linking together fewer temporal parts notice that the Agent missed (4) -, the mechanism delivered a different prediction: the ball is behind the occluder.

Fourth belief condition: (3) the ball continues to roll until it leaves the scene on the right; (4) the Agent leaves the scene; (4) the ball reappears from the right, and rolls back behind the occluder; (5) the Agent returns; (5) the occluder is lowered and the ball is there. In this condition ( $\mathrm{P}+\mathrm{A}-)$, Event Processor is again computing in first and in third person, and delivering different predictions. Both running in first and in third person, the module follows the same script: it tracks the present temporal part of the target event, it links temporal parts that were already present, and it predicts temporal parts that may be present shortly. A significant detail in third-person computing: what happens in the absence of that person, as well as temporal parts she can not track due to her position, gets not included. That is why predictions in third-person sometimes diverge from predictions in first person.

KTL were testing reaction time. Participants were instructed "to press a button as soon as they detected a ball" (p. 1831). The presence of the Agent and all the second-order believes ( $\mathrm{A}+$ or $\mathrm{A}-$ ) were irrelevant to the task. Nonetheless, the presence of someone else (even a character in an animation) seems to influence the 
reaction time: "participants detected the ball faster when they (and the agent) believed that the ball was behind the occluder" (p. 1832). On the other hand, the worst performance in terms of reaction time occurred in the second belief condition (when both Participant and Agent falsely believed the ball was not behind the occluder). Interestingly, reaction time did not differ significantly between the third and fourth belief conditions: "Both types of belief representations speed up the participants' RTs to similar extents" (p. 1832). This evidence speaks for the behavioral function I have proposed here: clearly, the ability to process from a different framework (in third person) maximizes fitness by reducing the reaction time.

Schneider et al. (2012a) released data confirming that humans automatically compute from a third-party framework, and that this process not only attributes beliefs (true or false), but also generates behavioral expectations. In another paper (Schneider et al., 2012b), they discuss situations in which the computation in thirdperson is temporarily suspended. It happens when the subject receives a parallel task (dual task method) - e.g. pay attention to a given sequence of letters etc. It looks like the computation in third person is suspended when the system gets somehow loaded in first-person. This is a topic for further investigation.

One might argue that computation in third-person is sort of a cognitive expansion due to language. Given that the processing of events from a third person's frame demands attribution of perceptual inputs and propositional attitudes, it seems reasonable to assume that such attributions are governed by principles. Along these lines, it makes sense to think the module undergoes a maturational process and, at a given moment, it adds or enables those principles. According to Carruthers (2016, p. 145), when a module adds or enables resources, "the system becomes more efficient in its operation over time, and interacts more robustly with surrounding mental faculties". This is another topic for future investigation.

\section{Concluding remarks}

Evolutionary psychology's hard-core, once taken as an architectonic claim (the human mind is massively modular), can be challenged with another architectonic claim: Eternalism (the world is a four-dimensional manifold). In addition to giving details of this challenge, this paper explored one possible solution: the human mind has a module for processing temporal parts of events. The computational explanation I have sketched highlights goals and a couple of behavioral functions of that hypothetical mechanism. I think there is room for such a module, both from an evolutionary and from a computational point of view.

\section{REFERÊNCIAS}

ANDERSON, J. R. The adaptive character of thought. Hillsdale: Erlbaum, 1990.

ARIETI, S. Schizophrenic cognition. Proceedings of the Annual Meeting of the American Psychopathological Association, v. 54, p. 37-48, 1966. 
ARSTILA, V. Temporal experiences without the specious present. Australasian Journal of Philosophy, v. 96, p. 287-302, 2018. https://doi.org/10.1080/00048402.2017.1337211

ARTHUR, R. Minkowski spacetime and the dimensions of the present. In: DIEKS, D. (Ed.) The ontology of spacetime. Amsterdam; Oxford: Elsevier, 2006. p. 129-155. https://doi.org/10.1016/S1871-1774(06)01007-2

BARRETT, H.; TODD, P.; MILLER, G.; BLYTHE, P. Accurate judgments of intention from motion alone: a cross-cultural study. Evolution and Human Behavior, v. 26, p. 313-331, 2005. https://doi.org/10.1016/j.evolhumbehav.2004.08.015

BIDET-ILDEI, C.; KITROMILIDES, E.; ORLIAGUET, J.; PAVLOVA, M.; GENTAZ, E. Preference for point-light human biological motion in newborns: contribution of translational displacement. Developmental Psychology, v. 50, p. 113-120, 2014. https://doi.org/10.1037/a0032956

$\mathrm{BIRCH}$, J. Natural selection and the maximization of fitness. Biological Review, v. 91, p. 712-727, 2016. http://dx.doi.org/10.1111/brv.12190

BOURNE, C. When am I? A tense time for some tense theorists? Australasian Journal of Philosophy, v. 80, p. 359-371, 2002. https://doi.org/10.1080/713659472

BUSS, D. Mate preference mechanisms: consequences for partner choice and intrasexual competition. In: BARKOW, J.; COSMIDES, L.; TOOBY, J. (Eds.) The adapted mind: evolutionary psychology and the generation of culture. New York; Oxford: Oxford University Press, 1992. p. 249-266.

BUSS, D. The evolution of desire: strategies of human mating. 3.ed. revised and updated. New York: Basic Books, 2016.

BUSS, D. Evolutionary psychology: the new science of the mind. 3.ed. Boston: Pearson Education, 2008.

CARRUTHERS, P. On Fodor-fixation, flexibility and human uniqueness. Mind and Language, v. 23 , p. 293-303, 2008. http://dx.doi.org/10.1111/j.14680017.2008.00344.x

CARRUTHERS, P. Two systems of mindreading? Review of Philosophy and Psychology, v. 7, p. 141-162, 2016. https://doi.org/10.1007/s13164-015-0259-y

CARRUTHERS, P. The architecture of mind. Oxford: Oxford University Press, 2006. https://doi.org/10.1093/acprof:oso/9780199207077.001.0001

CHESTER, D.; DEWALL, N. Adaptations to avoid ostracism. In: SHACKELFORD, T.; WEEKES-SHACKELFORD, V. (Eds.) Encyclopedia of evolutionary psychological science. New York: Springer, 2016. p. 01-02. https://doi.org/10.1007/978-3-31916999-6_1474-1

COSMIDES L.; TOOBY, J. Cognitive adaptations for social exchange. In: BARKOW, J.; COSMIDES, L.; TOOBY, J. (Eds.) The adapted mind: evolutionary psychology and the generation of culture. New York; Oxford: Oxford University Press, 1992. p. 163-228.

COSMIDES, L.; TOOBY, J. Origins of domain specificity: the evolution of functional organization. In: HIRSCHFELD, L.; GELMAN, S. (Eds.) Mapping the mind: domain specificity in cognition and culture. Cambridge: Cambridge University Press, 1994. p. 85-116. 
COSMIDES, L.; TOOBY, J.; BARKOW, J. Introduction: evolutionary psychology and conceptual integration. In: BARKOW, J.; COSMIDES, L.; TOOBY, J. (Eds.) The adapted mind: evolutionary psychology and the generation of culture. New York; Oxford: Oxford University Press, 1992. p. 03-18.

CRAIG, W. The metaphysics of special relativity: three views. In: CRAIG, W.; SMITH, Q. (Eds.) Einstein, relativity and absolute simultaneity. London: Routledge, 2008. p. 11-49.

DAVIES, N.; KREBS, J.; WEST, S. An introduction to behavioral ecology. 4.ed. Hoboken, NJ: Wiley-Blackwell, 2012.

DI LOLLO, V. Temporal integration in visual memory. Journal of Experimental Psychology, v. 109, p. 75-97, 1980. https://doi.org/10.1037/0096-3445.109.1.75

DI LOLLO, V.; WILSON, A. Iconic persistence and perceptual moment as determinants of temporal integration in vision. Vision Research, v. 18, p. 1607-1610, 1978. https://doi.org/10.1016/0042-6989(78)90251-1

EINSTEIN, A. On the electrodynamics of moving bodies. In: KOX, A.; KLEIN, M.; SCHULMANN, R. (Eds.) The collected papers of Albert Einstein, vol. 2: The Swiss years. Princeton: Princeton University Press, 1989. p. 140-171. http://einsteinpapers.press.princeton.edu/vol2-trans/154

EINSTEIN, A. On the special and general theory of relativity (a popular account). In: KOX, A.; KLEIN, M.; SCHULMANN, R. (Eds.) The collected papers of Albert Einstein, vol. 6: The Berlin years. Princeton: Princeton University Press, 1997. p. 274-420. http://einsteinpapers.press.princeton.edu/vol6-doc/448

EFFINGHAM, N. Endurantism and perdurantism. In: MANSON, N.; BARNARD, R. (Eds.) The continuum companion to metaphysics. London; New York: Continuum, 2012. p. 170-197.

ERAÑA, A. Dual process theories versus massive modularity hypotheses. $\begin{array}{lllll}\text { Philosophical Psychology, v. 25, p. } & 855-872,2 .\end{array}$ http://dx.doi.org/10.1080/09515089.2011.631994

FESSLER, D.; NAVARRETE, D. Domain-specific variation in disgust sensitivity across the menstrual cycle. Evolution and Human Behavior, v. 24, p. 406-417, 2003. http://dx.doi.org/10.1016/S1090-5138(03)00054-0

FODOR, J. The mind doesn't work that way. Cambridge: MIT Press, 2000.

FODOR, J. The modularity of mind. Cambridge: MIT Press, 1983.

FOUKS, L.; GUILBERT, S.; MONTOT, M. Minkowski's concept of lived time. Annales Médico-Psychologiques, v. 147, p. 801-809, 1989.

KOVÁCS, A.; TÉGLÁS, E.; ENDRES, A. The social sense: susceptibility to others' beliefs in human infants and adults. Science, v. 330, p. 1830-1834, 2010. https://doi.org/10.1126/science.1190792

KURZBAN, R.; LEARY, M. 2001. Evolutionary origins of stigmatization: the functions of social exclusion. Psychological Bulletin, v. 127, p. 187-208, 2001. https://doi.org/10.1037/0033-2909.127.2.187

LAKATOS, I. Falsification and the methodology of scientific research programs. In: LAKATOS, I.; MUSGRAVE, A. (Eds.) Criticism and the growth of knowledge. Cambridge: Cambridge University Press, 1970. p. 91-195. (1970a) 
LAKATOS, I. History of science and its rational reconstructions. Proceedings of the Biennial Meeting of the Philosophy of Science Association, v. 1970, p. 91-136, 1970. (1970b)

LIEBERMAN, D.; TOOBY, J.; COSMIDES, L. The architecture of human kin detection. Nature, v. 445, p. 727-731, 2007. https://doi.org/10.1038/nature05510

LITTLE, A.; TREBICKY, V.; HAVLICEK, J.; ROBERTS, S.; KLEISNER, K. Human perception of fighting ability: facial cues predict winners and losers in mixed martial arts fights. Behavioral Ecology, v. 26, p. 1470-1475, 2015. https://doi.org/10.1093/beheco/arv089

LIU, J.; CORBERA, S.; WEXLER, B. Neural activation abnormalities during selfreferential processing in schizophrenia: an fMRI study. Psychiatry Research: $\begin{array}{llllll}\text { Neuroimaging, } & \text { v. } & 222, & \text { p. } & 165-171, & 2014 .\end{array}$ http://dx.doi.org/10.1016/j.pscychresns.2014.04.003

MARR, D. Vision: a computational approach. San Francisco: Freeman \& Co., 1982.

MINKOWSKI, H. Space and time. In: LORENTZ, H.; EINSTEIN, A.; MINKOWSKI, H.; WEIL, H. (Eds.) The principle of relativity. Translated by W. Perrett and G. B. Jeffery. New York: Dover Publications, 1923. p. 73-91.

NEISSER, U. Five kinds of self-knowledge. Philosophical Psychology, v. 1, p. 3559, 1988. http://dx.doi.org/10.1080/09515088808572924

PARK, J.; SCHALLER, M.; VAN VUGT, M. Psychology of human kin recognition: heuristic cues, erroneous inferences, and their implications. Review of General Psychology, v. 12, p. 215-235, 2008. https://doi.org/10.1037/1089-2680.12.3.215

PAVLOVA, M. Biological motion processing as a hallmark of social cognition. Cerebral Cortex, v. 22, p. 981-995, 2012. https://doi.org/10.1093/cercor/bhr156

PEACOCKE, C. The mirror of the world: subjects, consciousness, and selfconsciousness. Oxford: Oxford University Press, 2014. https://doi.org/10.1093/acprof:oso/9780199699568.001.0001

PETKOV, V. Is there an alternative to the block universe view? In: DIEKS, D. (Ed.) The ontology of spacetime. Amsterdam; Oxford: Elsevier, 2006. p. 207-228. https://doi.org/10.1016/S1871-1774(06)01011-4

PINKER, S. How the mind works. New York: Norton \& Co., 1997.

PYLES, J.; GARCIA, J.; HOFFMAN, D.; GROSSMAN, E. Visual perception and neural correlates of novel 'biological motion'. Vision Research, v. 47, p. 2786-2797, 2007. https://doi.org/10.1016/j.visres.2007.07.017

QUINE, W. Word and object. Cambridge: MIT Press, 1960.

SCHNEIDER, D.; BAYLISS, A.; BECKER, S.; DUX, P. Eye movements reveal sustained implicit processing of others' mental states. Journal of Experimental Psychology, v. 141, p. 433-438, 2012. (2012a) https://doi.org/10.1037/a0025458

SCHNEIDER, D.; LAM, R.; BAYLISS, A.; DUX, P. Cognitive load disrupts implicit theory-of-mind processing. Psychological Science, v. 23, p. 842-847, 2012. (2012b) https://doi.org/10.1177/0956797612439070

SELL, A.; BRYANT, G.; COSMIDES, L.; TOOBY, J.; SZNYCER, D.; VON RUEDEN, C.; KRAUSS, A.; GURVEN, M. Adaptations in humans for assessing physical 
strength from the voice. Proceedings of the Royal Society B, v. 277, p. 3509-3518, 2010. https://doi.org/10.1098/rspb.2010.0769

SELL, A.; COSMIDES, L.; TOOBY, J.; SZNYCER, D.; VON RUEDEN, C.; GURVEN, $M$. Human adaptations for the visual assessment of strength and fighting ability from the body and face. Proceedings of the Royal Society B, v. 276, p. 575-584, 2009. https://doi.org/10.1098/rspb.2008.1177

SIDER, T. Temporal Parts. In: SIDER, T.; HAWTHORNE, J.; ZIMMERMAN, D. (Eds.) Contemporary debates in metaphysics. Oxford: Blackwell, 2008. p. 241-262.

SIDER, T. Four-dimensionalism: an ontology of persistence and time. Oxford: Oxford University Press, 2001. http://dx.doi.org/10.1093/019924443X.001.0001

SKOW, B. Objective becoming. Oxford: Oxford University Press, 2015. http://dx.doi.org/10.1093/acprof:oso/9780198713272.001.0001

SMART, J. Between science and philosophy. New York: Random House, 1968.

STANGHELLINI G., ROSFORT, R. Emotions and personhood: exploring fragility, making sense of vulnerability. Oxford: Oxford University Press, 2013.

TOOBY, J. The emergence of evolutionary psychology. In: PINES, D. (Ed.) Emerging syntheses in science. Santa Fe, NM: Santa Fe Institute, 1985. p. 66-73.

TROJE, N. Retrieving information from human movement patterns. In: SHIPLEY, T.; ZACKS, J. (Eds.) Understanding events: how humans see, represent, and act on events. Oxford: Oxford University Press, $2008 . \quad$ p. 308-334. http://dx.doi.org/10.1093/acprof:oso/9780195188370.003.0014

TROJE, N.; WESTHOFF, C. The inversion effect in biological motion: evidence for a life detector? Current Biology, v. 16, p. 821-824, 2006. http://dx.doi.org/10.1016/j.cub.2006.03.022

TYBUR, J.; LIEBERMAN, D.; GRISKEVICIUS, V. Microbes, mating, and morality: individual differences in three functional domains of disgust. Journal of Personality $\begin{array}{llllll}\text { and Social Psychology, v. 97, p. 103-122, } 2009 . & \text { v. }\end{array}$ http://dx.doi.org/10.1037/a0015474

URFER, A. Phenomenology and psychopathology of schizophrenia: the views of Eugene Minkowski. Philosophy, Psychiatry and Psychology, v. 8, p. 279-289, 2001. https://doi.org/10.1353/ppp.2002.0029

WEIL, $\mathrm{H}$. Philosophy of mathematics and natural science. Princeton: Princeton University Press, 1949.

WILLIAMS, D. The myth of the passage. Journal of Philosophy, v. 48, p. 457-472, 1951. https://dx.doi.org/10.2307/2021694 